\title{
SOSIALISASI PENGGUNAAN APLIKASI ZOOM MEETING DAN GOOGLE CLASSROOM PADA GURU DI SDN 17 MATA AIR PADANG SELATAN
}

\author{
Oleh \\ Suhery ${ }^{1)}$, Trimardi Jaya Putra ${ }^{2)}$ \& Jasmalinda ${ }^{3)}$ \\ ${ }^{1,2,3}$ Sekolah Tinggi Ilmu Ekonomi Perdagangan \\ Email : ${ }^{1}$ suheriasia@gmail.com
}

\begin{abstract}
Abstrak
Tujuan dari kegaitan pelatihan agar guru di SDN 17 Mata Air Padang Selatan bisa melakukan pembelajaran daring secara online melalui rumah tanpa tatap muka langsung dengan siswa.Metode yang dipilih dengan cara memberikan pelatihan. Hasil dari kegiatan pengabdian masyarakat ini adalah panduan praktis dan sederhana berupa pedoman bagi guru di SDN 17 Mata Air Padang Selatan untuk paham dan mengerti menggunakan aplikasi zoom meeting dan google classroom.
\end{abstract}

Kata kunci : Pelatihan, Zoom Meeting \& Google Classroom.

\section{PENDAHULUAN}

Di tengah masa Pandemi Covid-19 ini kebijakan pemerintahan memberlakukan belajar dari rumah yaitu pembelajaran secara daring. Secara tiba-tiba pembelajaran di sekolah yang semula yang sifatnya tatap muka berubah menjadi pembelajaran secara daring. Hal ini membuat semua dari tenaga pendidik harus mengikuti kebijakan dari pemerintah untuk belajar mengajar secara daring.

Dengan adanya aplikasi zoom meeting dan google classroom untuk media pembelajaran secaradaring. Bagisebagian orang Indonesia aplikasi zoom meeting dan google classroom mungkin masih dianggap baru. Penggunaan aplikasi zoom meeting dan google classroomdapat digunakan di smartphone. Hanya saja, saat diaplikasikan pada sesuatu yang baru dan bersifat pengajaran serta pembelajaran, tentu belum semua dapat mencernanya dengan baik.

Tantangan alih sistem pembelajaran dari tatap muka menjadi daring inilah yang membuat Tim PKM STIE Perdagangan ingin mengangkat tema ini. Mengingat, selama ini pembelajaran di Sekolah Dasar, memang hanya dilakukan secara offline atau tatap muka. Tim PKM STIE Perdagangan mengadakan pelatihan mengajar melalui Zoom Meeting dan Google Classroom terhadap tenaga pendidik di SDN 17 Mata Air Padang Selatan.

Untuk itu, maka tim PKM Sekolah Tinggi Ilmu Ekonomi Perdagangan (STIE-P) merasa bertanggungjawab untuk bersama-sama sosialisasi penggunaan aplikasiZoom Meeting dan Google Classroom terhadap tenaga pendidik di SDN 17 Mata Air Padang Selatan. Rumusan masalah yang akan dibahas adalah:

1. Kurangnya pemahaman dan pengetahuan tenaga pendidik di SDN 17 Mata Air Padang Selatan tentang pemakaian Zoom Meeting dan Google Classroom.

2. Terkendala kondisi sebagian guru di SDN 17 Mata Air Padang Selatan yang gagap teknologi atau gaptek dalam penguasaan teknologi informasi (TI).

Tujuan yang ingin dicapai dari kegiatan pengabdian pada masyarakat ini adalah:

1. Membekali tenaga pendidik SDN 17 Mata Air Padang Selatan agar memiliki pemahaman dan pengetahuan tentang Zoom Meeting dan Google Classroom.

2. Membantu memberikan pengetahuan dan pemahaman tentang pemakaian Zoom Meeting dan Google Classroom.

3. Memberikan contoh cara pemakaian Zoom Meeting dan Google Classroom. 
Manfaat yang diharapkan dari kegiatan pegabdian masyarakat ini adalah:

1. Peserta memahami pengetahuan pemakaian Zoom Meeting dan Google Classroom untuk diterapkan pada saat mengajar siswa/siswi.

2. Peserta menyadari akan pentingnya pengetahuan pemakaian Zoom Meeting dan Google Classroom agar mudah cara pembelajaran secara daring.

3. Peserta mengetahui dan memahami caraZoom Meeting dan Google Classroom.

\section{LANDASAN TEORI \\ Pembelajaran Daring}

Pembelajaran daring adalah sebuah proses pembelajaran yang berbasis elektronik. Salah satu media yang digunakan adalah jaringan smartphone dan komputer. Dengan dikembangkannya di jaringansmartphone dan komputer memungkinkan untuk dikembangkan dalam bentuk berbasis web, sehingga kemudian dikembangkan ke jaringan komputer yang lebih luas yaitu internet. Penyajian pembelajaran daring berbasis web ini bisa menjadi lebih interaktif. Sistem pembelajaran daring ini tidak memiliki batasan akses, inilah yang memungkinkan pembelajaran bisa dilakukan lebih banyak waktu.

Kelebihan pembelajaran secara daring memiliki kelebihan sebagai berikut:

1. Tersedianya fasilitas emoderating dimana pengajar dan siswa dapat berkomunikasi secara mudah melalui fasilitas internet secara reguler atau kapan saja kegiatan berkomunikasi itu dilakukan tanpa dibatasi oleh jarak, tempat, dan waktu.

2. Pengajar dan siswa dapat menggunakan bahan ajar yang terstruktur dan terjadwal melalui internet .

3. Siswa dapat belajar (me-review) bahan ajar setiap saat dan dimana saja apabila diperlukan mengingat bahan ajar tersimpan di komputer.

4. Bila siswa memerlukan tambahan informasi yang berkaitan dengan bahan yang dipelajarinya, ia dapat melakukan akses di internet.

5. Baik pengajar maupun siswa dapat melakukan diskusi melalui internet yang dapat diikuti dengan jumlah peserta yang banyak.

6. Berubahnya peran siswa dari yang pasif menjadi aktif.

7. Relatif lebih efisien. Misalnya bagi mereka yang tinggal jauh dari Perguruan Tinggi atau sekolah konvensional dapat mengaksesnya

Kekurangan pembelajaran daring juga tidak terlepas dari berbagai kekurangan, yaitu sebagai berikut:

1. Kurangnya interaksi antara pengajar dan siswa atau bahkan antara siswa itu sendiri, bisa memperlambat terbentuknya values dalam proses belajar mengajar.

2. Kecenderungan mengabaikan aspek akademik atau aspek sosial dan sebaliknya mendorong aspek bisnis atau komersial.

3. Proses belajar dan mengajarnya cenderung ke arah pelatihan dari pada pendidikan.

4. Berubahnya peran guru dari yang semula menguasai teknik pembelajaran konvensional, kini dituntut untuk menguasai teknik pembelajaran dengan menggunakan ICT (Information Communication Technology).

5. Siswa yang tidak mempunyai motivasi belajar yang tinggi cenderung gagal.

6. Tidak semua tempat tersedia fasilitas internet (berkaitan dengan 
masalah tersedianya listrik, telepon, dan komputer). (Taufik.net, 2010)

\section{METODE KEGIATAN}

\section{Permasalahan}

Kegiatan belajar-mengajar jarak jauh masih terkendala kondisi sebagian guru yang gagap teknologi atau gaptek dalam menggunakan perangkat komunikasi. Dinas Pendidikan (Disdik) Kota Padang mengakui masih adanya masalah tersebut. Permasalahan dalam pembelajaran daring adalah kemampuan guru dalam penguasaan teknologi informasi (TI). Padahal, ini sangat diperlukan mengingat pandemi Covid-19 belum jelas kapan akan berakhir.Untuk mengatasi persoalan tersebut, tim PKM Sekolah Tinggi Ilmu Ekonomi Perdagangan (STIE-P) mencoba membantu mitra dengan memberikan pengetahuan dan pemahaman aplikasi zoom meeting dan google classroom.

\section{Pemecahan Masalah}

Adapun Metode yang dilakukan dalam pelatihan pembelajaran daring ini adalah dengan cara pelatihan secara langsung. Tujuannya agar guru dapat memahami materi pelatihan dengan baik dan bisa mempraktikkannya secara langsung. Langkah-langkah yang dilakukan pada kegiatan pelatihan ini adalah:

1. Menerapkan protokol Kesehatan sebelum, Ketika dan sesudah melakukan pelatihan.

2. Memperkenalkan tentang pembelajaran daring.

3. Menjelaskan tentang zoom meeting dan google classroom beserta cara penggunaannya.

\section{Khalayak Sasaran}

Khalayak sasaran sosialisasi penggunaan aplikasi zoom meeting dan google classroom pada guru di SDN 17 Mata Air Padang, dengan jumlah guru yang diikutsertakan dalam pelatihan ini sebanyak 10 orang.

\section{Perencanaan Materi}

Sebagai pendahuluan dalam kegiatan ini, maka dilakukan konfirmasi terkait dengan media yang dimiliki guru untuk dijadikan media dalam proses pembelajaran daring apakah berupa HP atau laptop. Karena rata-rata guru menggunakan HP, maka sebelum menjelaskan bagaimana cara menggunakanzoom meeting dan google classroom dalam proses pembelajaran, guru diminta untuk mendownload aplikasi pembelajaranzoom meetingdan google classroom melalui play store.Setelah semua selesai menginstall aplikasizoom meeting dan google classroom, selanjutnya dijelaskan Langkah-langkah penggunaan zoom meeting dan google classroom.

5. Waktu dan Tempat Pelaksanaan

Pelaksanaan kegiatan pengabdian masyarakat ini dilaksanakan pada pada tanggal 17 Juni 2020, bertempat di SDN 17 Mata Air Padang Selatanmerupakan tenaga pendidik.

6. Pemateri dan Pelaksana Kegiataan Pelatihan diberikan oleh dosen Sekolah Tinggi Ilmu Ekonomi Perdagangan.

Tabel 1. Daftar Nama Narasumber dan Instruktur Kegiatan Pengabdian

\begin{tabular}{|l|l|l|}
\hline No & \multicolumn{1}{|c|}{ Nama } & \multicolumn{1}{|c|}{$\begin{array}{c}\text { Tugas } \\
\text { Dalam } \\
\text { Tim }\end{array}$} \\
\hline 1 & $\begin{array}{l}\text { Thesa Alif Ravelby, SE., } \\
\text { MM }\end{array}$ & Pemateri \\
\hline 2 & $\begin{array}{l}\text { Yoserizal, SHI., MM } \\
\text { Agus Nurofik, S.Kom., }\end{array}$ & Pemateri \\
\hline 3 & $\begin{array}{l}\text { Instruktur } \\
\text { MM }\end{array}$ & Sutiyem, SE., MM \\
\hline 4 & Instruktur \\
\hline
\end{tabular}

\section{HASIL DAN PEMBAHASAN Hasil Pengabdian Masyarakat}

Adapun Metode yang dilakukan dalam pelatihan pembelajaran daring ini adalah dengan cara pelatihan secara langsung. Tujuannya agar guru dapat memahami materi pelatihan dengan baik dan bisa mempraktikkannya secara langsung. Langkah-langkah yang dilakukan pada kegiatan pelatihan ini adalah: 
1. Menerapkan protokol Kesehatan sebelum, Ketika dan sesudah melakukan pelatihan.

Dalam proses pelaksanaan pelatihan para guru dengan teratur mengikuti protokol Kesehatan yang sudah dibuat oleh panitia pelaksana. Dari mulai pengecekan suhu tubuh, menjaga jarak, memakai masker selama pelaksanaan pelatihan dan tidak berkumpul di satu tempat sebelum. ketika dan sesudah pelatihan.

2. Memperkenalkan tentang pembelajaran daring.

Pada bagian ini pemateri menyampaikan tentang berbagai media yang dipergunakan dalam pembelajaran daring termasukzoom meeting dan google classroom. Dari penjelasan yang disampaikan para peserta telah memahami kekurangan dan kelebihan dari masing-masing aplikasi pembelajaran yang dijelaskan.

3. Menjelaskan tentang zoom meeting dan google classroom beserta cara penggunaannya.

a. Membuka aplikasi zoom meeting dan google classroom

b. Membuat kelas

c. Mengcopy kode kelas

4. Praktik pengunaanzoom meeting dan google classroom

\section{PENUTUP}

\section{Kesimpulan}

Dari kegiatan pengabdian yang telah dilakukan, maka diperoleh hasil bahwa peserta sangat berminat dengan pelatihan ini. Penambahan pengetahuan bagi peserta tentang penggunaan aplikasi zoom meeting dan google classroomyang baik dan benar, serta secara cepat dengan menerapkan secara langsung.

\section{DAFTAR PUSTAKA}

[1] Airtanah, A. (2014). Bab ii kajian teori. Bab Ii Kajian Teori, (1), 9-34.

[2] Riadi, M. (2014). Pengertian , Karaktiristik dan Manfaat E-. 4-6. SATRIO, A. (2011). Kendala Dan Penerapan E-Learning. Journal Information, 10, 1-16.

[3] Setiawan, P. (2020). Pengertian E-learning Pengertian E-learning Menurut Para Ahli Karakteristik E-learning Manfaat Elearning.

[4] Taufik.net. (2010). Kelebihan Dan Kekurangan. 1-7. 